\title{
AS DIMENSÕES E O USO DO CONHECIMENTO COMO POTENCIALIZADORES DA COMPETITIVIDADE E CRESCIMENTO DA FIRMA
}

\author{
Lídia Silveira Arantes ${ }^{1}$ \\ Orlando Martinelli Junior ${ }^{2}$ \\ Thales de Oliveira Costa Viegas ${ }^{3}$
}

\section{RESUMO}

Este trabalho busca ampliar a compreensão acerca do conhecimento no âmbito empresarial, num contexto em que a economia do conhecimento se tornou uma importante arma competitiva. As firmas de vanguarda apresentam processos de gestão do conhecimento como elemento estratégico de seus negócios locais ou globais. O objetivo deste trabalho é compreender como a interconexão entre as dimensões (tácita e explícita) do conhecimento são relevantes para a geração de capacidades competitivas organizacionais. Enfatizam-se os incentivos para a sua criação e difusão, verificados no âmbito das empresas. Esse recorte temático se justifica pela relevância do conhecimento, concebido como um ativo intangível, necessário para engendrar inovações. Para atender os objetos da pesquisa, foi realizada uma revisão teórica heterodoxa que trata do conceito de conhecimento organizacional. Ademais, discute-se o modelo teórico de Nonaka e Takeuchi (N\&T), que se propõe a realizar uma análise aprofundada do referido tema, além de sistematizar um modelo de gestão de conhecimento organizacional.

Palavras-chave: Conhecimento, organizações e gerenciamento.

\begin{abstract}
The purpose of this paper is to broaden the understanding of knowledge in the business environment, in a context in which the knowledge economy has become an important competitive weapon. Leading companies present knowledge management processes as a strategic element of their local or global business. The aim of this article is to understand how the interconnection between the (tacit and explicit) dimensions of knowledge are relevant to the generation of organizational competitive capacities. Emphasis is given to the incentives for the knowledge creation and diffusion within companies. This research issue is justified by the relevance of knowledge, conceived as an intangible asset, necessary to engender innovations. In order to meet the objectives of the research, a heterodox theoretical revision was carried out, dealing with the concept of organizational knowledge. In addition, we discuss the theoretical model of Nonaka and Takeuchi ( $\mathrm{N} \& \mathrm{~T}$ ), which proposes to carry out an in-depth analysis of this theme, besides systematizing an organizational knowledge management model. In addition, empirical research related to this model is presented.
\end{abstract}

Keywords: knowledge, firm and management

Área Temática 5.4: Economia do Conhecimento

JEL: D83 Search; Learning; Information and Knowledge

\footnotetext{
${ }^{1}$ Mestranda pelo Programa de Pós-Graduação em Economia e Desenvolvimento (PPGE\&D), UFSM, lidiaarantes@gmail.com

${ }^{2}$ Professor Associado Departamento de Economia, UFSM, orlando.martinelli@gmail.com

${ }^{3}$ Professor Adjunto do Departamento de Economia, UFSM, thales.viegas@gmail.com
} 


\section{INTRODUÇÃO}

As teorias heterodoxas apresentam-se, na microeconomia, como abordagens que ampliam o debate acerca da heterogeneidade das firmas. Essas diferenças podem ser explicações plausíveis para a existência de inovação. Nesta perspectiva, o processo de inovação é considerado como uma combinação de fatores internos da firma. Estes fatores podem se apresentar como, por exemplo: rotinas organizacionais, capacidades tecnológicas, diversidade de estratégias de negócio e esforços deliberados para inovação. Todos esses elementos envolvem coordenação e gestão do conhecimento intrafirma. Por isso, a gestão de conhecimento se constitui em estratégias pautadas no aprendizado. As firmas que investem e valorizam os mecanismos de aprendizagem têm respaldo para a sua contínua adaptação e renovação no ambiente de negócios, de modo a ampliar a sua longevidade (MARINS, 2007). O cenário competitivo no qual as firmas estão inseridas configura-se pela necessidade de criação e renovação de vantagens competitivas. $O$ desempenho das empresas é resultado desses diferenciais, os quais derivam da capacidade de criação de conhecimento (NONAKA \& TAKEUCHI, 1997).

Nesta ótica, o processo de constituição de novos conhecimentos e aprendizados é buscado com vistas a gerar diferenciais competitivos. A base de conhecimento representa o conjunto de habilidades, conhecimentos e competências que compõe a firma e representam, muitas vezes, a busca por soluções para se manter no mercado. As variações nesta base envolvem diferentes graus de conhecimento tácito que convergem para a explicação dos aspectos destoantes interfirma. A capacidade de gerenciar, distribuir e criar o conhecimento com eficiência/eficácia é essencial para que uma firma se coloque em posição competitiva favorável (LEONARDI, 2016).

O objetivo precípuo deste trabalho é apresentar algumas contribuições da literatura heterodoxa no sentido de compreender como as interconexões entre as dimensões (tácita e explícita) do conhecimento são capazes de gerar elou potencializar as capacidades competitivas e o processo de crescimento das firmas. Especialmente destaca-se o modelo conversão de conhecimento de Nonaka e Takeuchi (N\&T). A pesquisa se justifica pela relevância dada à gestão do conhecimento no âmbito de um contexto econômico e organizacional. Uma gestão adequada que a definição, sistematização e medição do conhecimento organizacional pode levar à maior clareza das iniciativas que podem ser implementadas pelas empresas no âmbito de seus processos estratégicos e competitivos. Essa gestão pode transformar ativos intangíveis (como conhecimento e aprendizado) em ativos estratégicos (Nelson e Winter, 1982) que representam fonte de vantagem competitiva (NONAKA E TAKEUCHI, 1995). Adicionalmente, a gestão de conhecimento é capaz de melhorar o desempenho dos processos da firma (ARAÚJO, 2009). Para que isso ocorra é necessário investir em capital intelectual, com vistas a resolver problemas a partir do fomento a soluções criativas e sustentáveis (CARVALHO e FERREIRA 2012).

\section{O CONHECIMENTO EM SUAS DIMENSÕES EXPLÍCITAS E TÁCITAS}

O conhecimento apresenta-se economicamente como um insumo produtivo do processo de criação de valor das organizações (LENHARI, 2005) Por isso, é capaz de criar diferenciais competitivos relevantes. Essa relevância é especialmente importante na interação entre conhecimento tático e codificado, pois a codificação pode cooperar para mudanças organizacionais significativas. Além disso, o investimento em conhecimento pode ser traduzido em aprendizado contínuo para indivíduos e firmas, de modo a promover a aquisição de conhecimento tácito (BROOKS e SMITH, 2000). Adicionalmente, cabe às empresas desenvolver estratégias para ampliar as relações e trocas de conhecimento entres os seus empregados, com vistas a promover a aprendizagem interativa (LUNDVALL, 2006).

O indivíduo possui papel central na teoria do conhecimento, pois é ele quem possui capacidade de análise, de síntese, e de representação, a consciência e, portanto, capaz de desempenhar atividades que envolvem a sensibilidade e o intelecto. Ao perceber as diferenças nos objetos e atribuir significado às coisas, pode elaborar ideias, conceitos, teorias, entre outras coisas. A partir da reflexão é capaz de conhecer-se a si mesmo e ao mundo externo. Desta forma, pode demostrar habilidades de percepção, imaginação, memória, fala e pensamento (CHAUI, 2000). 
Desde a Grécia Antiga já havia a clivagem do conhecimento nos seguintes elementos: i) abstrato, relacionado aos "olhos da alma" e; ii) empírico, associado à fenômenos concretos. O último, definido como conhecimento prático, estava ligado ao trabalho e à execução de atividades de produção de bens e itens necessários para viver. O primeiro, estabelecido como conhecimento teórico, associado ao prazer do saber, não estava relacionado com a praticidade específica, ou qualquer transformação em um objeto concreto. Essa diferença advém da separação de atividades de classe da época, que levou a uma fragmentação denominada "cabeça e mão", ou seja, uma analogia entre a relação do saber referente ao pensamento (que está na cabeça) e o executado de fato (que está na mão). O aparecimento da classe ociosa fez com que o conhecimento fosse desmembrado da aplicação prática ou da satisfação de necessidade material específica. Desta forma, como essa classe estava vinculada à noção de prestígio e status, essa prática do "pensar sem finalidade material imediata" foi considerada superior, pura e livre, em oposição ao trabalho prático (considerado neste contexto histórico inferior) (CARVALHO, 2008).

O conhecimento tácito é adquirido pela experiência, é subjetivo - difícil de ser reproduzido. O conhecimento explícito possui caráter codificado, que pode ser reproduzido a partir de treinamentos (capacitações), práticas e simulações (ex.: pilotar avião e executar cirurgias). Com isso, pode ser transferido e armazenado, bem como pode melhorar a eficiência das transações, apesar dos custos envolvidos no processo (FORAY, 2007). O conhecimento codificado pode ser explicitado em códigos, padrões, regras, entre outros, que possuem aceitação e utilização comum (COWAN, DAVID \& FORAY, 2000). O conhecimento tácito e o conhecimento explícito não são entidades totalmente separadas, mas mutuamente aderentes. Eles interagem e se intercalam entre si nas atividades criativas dos seres humanos (NONAKA, TAKEUCHI \& UMEMOTO 1996).

O conhecimento necessita ser transformado dentro da firma, caso contrário, será apenas um aglomerado de informações. Esse é o maior desafio das empresas, o de criar uma estrutura capaz de compartilhar o conhecimento. E é nesse enfoque que se faz necessário conhecer as dimensões do conhecimento, para que se seja possível criar mecanismos para seu aprimoramento, a fim de tornar o compartilhamento profícuo na geração de capacidades competitivas que sejam difíceis de imitar (TOMAÉL, ALCARÁ E DI CHIARA, 2005). Os obstáculos enfrentados pelas firmas que tentam imitar um ativo estratégico estão relacionados à natureza tácita e socialmente complexa do processo pelo qual ele foi acumulado. Neste sentido, os estoques de ativos estratégicos são acumulados por trajetórias escolhidas ao longo do tempo (DIERICKX E COOL, 1989).

Não se pode considerar o conhecimento como sendo um simples acúmulo de informações, mesmo que todas as mensagens recebidas pelo cérebro possam ser compiladas em um depositório. O conhecimento deve ser concebido como uma estrutura, um padrão complexo e livre, com suas partes conectadas de várias maneiras por laços de diferentes graus de sinergia. A informação é fragmentada e transitória, enquanto o conhecimento é estruturado, coerente e de significado persistente. Ademais, a informação é adquirida ao ser informada, enquanto o conhecimento pode ser adquirido no ato de pensar. Qualquer tipo de experiência, impressão acidental, observação e até experiência "interna" (que envolve sentimentos e pensamentos, por exemplo), não induzida por estímulos recebidos do meio ambiente, pode iniciar processos cognitivos que levem a mudanças no conhecimento de uma pessoa. Assim, novos conhecimentos podem ser adquiridos sem que sejam recebidas novas informações (ANCORI, BURETH \& COHENDET, 2000).

Como o foco da teoria é o sujeito, o conhecimento tácito adquire papel central. Em uma das principais obras de Polanyi, intitulada The Tacit Dimension, publicada em 1966, o autor afirma que o conhecimento é algo intuitivo. Para Polanyi a ciência é um processo que visa explicar o entendimento tácito intuitivo, o qual foi conduzido pela aprendizagem subconsciente do cientista. Segundo ele, a origem de todo conhecimento reside na intuição individual. $\mathrm{O}$ conhecimento depende a priori das habilidades perceptivas do indivíduo (ANCORI, BURETH \& COHENDET, 2000).

Polanyi (1966) esclareceu que a "dimensão tácita" é uma parte do conhecimento humano distinta, mas complementar ao conhecimento explícito nos processos cognitivos conscientes. Além disso, discorreu a respeito do conhecimento ser algo socialmente construído pelo indivíduo, a partir de novas experiências pessoais, que podem ser assimiladas por intermédio do conhecimento tácito. A experiência propicia adaptação aos novos conceitos e se funde com os conhecimentos já estabelecidos (COWAN, DAVID \& FORAY, 2000).O conhecimento humano, a partir da linguagem, adquire forma metafórica e releva que 
cada indivíduo escolhe metáforas diferentes para expressar o seu conhecimento. A percepção é o ponto chave para a ligação entre criatividade humana e mecanismos fisiológicos (POLANYI, 1966). Desta forma, o objetivo da próxima seção é apresentar discussão aprofundada a respeito das dimensões do conhecimento. O conhecimento não está disponível livremente, ou seja, ele não é amplamente acessível a todos, principalmente o conhecimento tácito que está "presente" na mente dos seres humanos (COWAN, DAVID \& FORAY, 2000).

Já o conhecimento codificado pode ser explicitado em códigos, padrões, regras, dentre outros, que possuem aceitação e utilização comum serve como um depositório de armazenamento. No entanto, as informações codificadas só podem desempenhar as funções acima citadas se as pessoas forem capazes de interpretá-las. Diante disso, a codificação depende da capacidade de "leitura" dos códigos pelos seres humanos e essa habilidade pode requerer a aquisição prévia de conhecimentos especializados consideráveis (possivelmente incluindo conhecimento não escrito em lugar algum). Desta forma, é interessante entender que, em geral, não há motivos para supor que todas as pessoas do mundo possuem o conhecimento necessário para interpretar os códigos adequadamente. Isso significa que o que é codificado para um grupo pode ser tácito para o outro e ainda um terceiro grupo não conseguir realizar essa distinção. Nesse sentido, o contexto cultural, social, relacionados a tempo e espaço distintos são considerações relevantes para a definição de conhecimento codificado (COWAN, DAVID \& FORAY, 2000).

Para ser tratado como um bem econômico, o conhecimento deve ser posto em ambiente que possibilite que ele circule e seja trocado. O processo de codificação permite que o conhecimento seja tratado e reduzido à informação, de acordo com as ferramentas e padrões da economia. Esta abordagem trata o conhecimento como um objeto com características discerníveis e mensuráveis (ANCORI, BURETH \& COHENDET, 2000).

A codificação é um processo que tipicamente envolve a criação de modelos, uma vez que a "modelagem" é um pré-requisito para transformar esse conhecimento em informação. Isso significa que esta prática não pode ser considerada como uma simples operação de transferência ou tradução. Sempre há um aspecto da criação. A codificação geralmente implica transformações na forma como o conhecimento é organizado. Assim, porque envolve a criação, a codificação é um processo irreversível, uma vez que o conhecimento se transforma em informação, não é possível retornar ao estado tácito original (COWAN \& FORAY, 1997).

A relação entre o conhecimento codificado e tácito é complementar e não substituta. Eles interagem e se intercalam entre si nas atividades criativas dos seres humanos (NONAKA, TAKEUCHI \& UMEMOTO 1996; ANCORI, BURETH \& COHENDET, 2000; COWAN \& FORAY, 1997). O processo de codificação não fornece todo o conhecimento necessário para realizar a ação, ou seja, sempre haverá algum conhecimento tácito envolvido para concretizar uma ação. É por isso que a codificação não pode ser considerada uma simples transferência de conhecimento do domínio tácito para o codificado. Constitui-se na construção de novos conjuntos de conhecimentos. Em outras palavras, a codificação nunca está completa e algumas formas de conhecimento tácito sempre continuarão a desempenhar um papel importante (COWAN \& FORAY, 1997).

A empresa deve desenvolver, conjuntamente, novas tecnologias e estruturas organizacionais que reproduzirão conhecimentos antigos e criarão novos. Em todos os casos, aonde são necessárias operações de transferência, recombinação, descrição, memorização e adaptação do conhecimento existente, seria muito oneroso e ineficiente manter esse conhecimento tácito. Se existe uma grande comunidade de agentes ativos que geram conhecimento codificado em um determinado idioma, utilizando de modelos específicos, será útil aprender esse idioma e esses modelos. Se houver apenas alguns desses agentes os benefícios serão muito menores (COWAN E FORAY, 1997).

É necessária uma melhor compreensão dos mecanismos que operam implicitamente no fenômeno da codificação, especialmente os mecanismos cognitivos e organizacionais mobilizados pelo processo de codificação. De fato, se os economistas não considerarem esses mecanismos (que geralmente são estudados por outras disciplinas, como a psicologia), existe o risco de se interpretar erroneamente alguns aspectoschave da codificação do conhecimento. Enfatiza-se que o conhecimento depende muito das habilidades cognitivas dos atores que o detêm e que não pode ser separado do processo de comunicação através do qual ele é trocado (ANCORI, BURETH \& COHENDET, 2000). 
A transformação que ocorre entre o conhecimento individual e coletivo adquire caráter essencial para o entendimento dos processos de conversão relacionados ao conhecimento. A formação e o uso do conhecimento dependem da natureza das organizações e outros conjuntos coletivos. Considerando o conhecimento como resultado de um processo social, podem ser levantadas questões relevantes, em particular, relativas à necessidade de entender como o conhecimento pode ser transmitido do nível da firma a um indivíduo e vice-versa (ANCORI, BURETH \& COHENDET, 2000). Esta transmissão requer diferentes mecanismos de conversão (tácito para codificado, codificado para tácito, etc.) para operar dentro de uma determinada firma e entre diferentes organizações. Nesta lógica é enfatizada a relação entre o individual/coletivo, que está conectada com a dimensão tácita/codificada (NONAKA TAKEUCHI, 1995).

As capacidades cognitivas dos agentes (o sentimento de similaridade, a sensibilidade aos sinais externos ou a imaginação) determinarão, fortemente, a forma como o conhecimento é adquirido e acumulado, bem como o modo que ele produz diferentes significados. Neste sentido, o processamento do conhecimento é altamente especifico e pessoal. O reconhecimento dessa questão explica porque a maioria dos trabalhos sobre a formação do conhecimento se concentra no indivíduo. Além disso, como a especialização das atividades de produção requer um aumento das trocas industriais, a especificidade da estrutura de conhecimento individual impõe interações interpessoais. Se, em determinando momento, cada indivíduo possui algum conhecimento específico e/ou especializado, é necessário "mobilizar" (socializar) todos esses elementos para que não fiquem dispersos. O conhecimento, ademais, resulta de um processo de construção social, relacionado a uma gama de propriedades peculiares (ANCORI, BURETH \& COHENDET, 2000).

Conforme abordado nessa seção, os conhecimentos tácito e/ou codificado são, em grande medida, complementares, uma vez que há limites para se codificar o conhecimento. Ademais, cumpre destacar que a codificação jamais ocorre de forma completa, e o conhecimento tácito continua desempenhando um papel relevante. Além disso, mesmo a significativa codificação do conhecimento, que ocorre de forma crescente, não reduz, necessariamente, a importância do conhecimento tácito (LENHARI, 2005).

Há ainda, debates teóricos relevantes na literatura relativa à gestão do conhecimento. Nota-se que a abordagem tradicional adota uma visão de conhecimento em linha com a escola racionalista. Essa perspectiva permite a redução do conhecimento à informação ou, mais precisamente, possibilita que o conhecimento seja considerado apenas um estoque de informações. Embora haja o reconhecimento de que o conhecimento seja valoroso para a firma, ainda há gargalos quanto ao seu gerenciamento ativo nas organizações. Há necessidade de pesquisa e discussões práticas de como ele pode ser gerenciado e utilizado com maior eficiência na rotina diária (DAVENPORT, 1998). A próxima seção contêm a discussão acerca do conhecimento e suas dimensões à luz de abordagens heterodoxas da firma.

\section{O CONHECIMENTO NAS ABORDAGENS HETERODOXAS DA FIRMA}

As teorias heterodoxas da firma, de forma geral, tratam da relevância do aprendizado e do conhecimento, bem como dissertam a respeito do papel do indivíduo nesse processo. Penrose (1959) foi pioneira ao destacar a relevância do conhecimento para a construção de capacidades, recursos e competências da firma. Nelson e Winter (1982) inserem o conceito de rotina, Giovani Dosi (1982) faz contribuições relevantes ao tratar o paradigma tecnológico, Lundvall (2006) enfatiza a relevância da aprendizagem para a gestão de conhecimento. Em conformidade com as teorias apresentadas, a teoria de Nonaka \& Takeuchi (1997) busca sistematizar a gestão de conhecimento organizacional. Apesar da importância evidente do conhecimento na economia e a sua importância para as inovações, em geral, e nas transformações tecnológicas, em particular, os teóricos do mainstream não incorporam o conhecimento e a aprendizagem como elementos centrais de sua teoria. Já nas teorias heterodoxas, o conhecimento atua como base para a existência de diferenciações entre as empresas e as suas dimensões (tácita e explícita) como essenciais para geração de diferenciais competitivos e de inovações.

Neste sentido, a inovação é uma atividade permeada de conhecimento. De acordo com Davepont e Prusak (1998 p. 6), 
O conhecimento é uma mistura fluida de experiência condensada, valores, informação contextual e insight experimentado, a qual proporciona uma estrutura para a avaliação e incorporação de novas experiências e informações. Ele tem origem e é aplicado na mente dos conhecedores. Nas organizações, ele costuma estar embutido não só em documentos ou repositórios, mas também em rotinas, processos práticas e normas organizacionais.

O trabalho de Penrose (1959) representa um marco relacionado aos estudos do conhecimento e sua relação com o crescimento da firma. A autora entende a firma como repositório de recursos tanto intangíveis quanto físicos. Estes últimos são denominados como uma coleção de recursos produtivos que abarca elementos tangíveis, como unidades fabris, equipamentos, terra e recursos naturais, matérias-primas, produtos semiacabados e recursos humanos disponíveis numa firma. (POPADIUK e RICCIARDI, 2011). Penrose foi pioneira em compreender a firma com base em suas capacidades (organizational capabilities) e abordá-la como organização administrativa e colecionadora de recursos. Desta forma, os recursos são fatores que impulsionam a firma, mas são limitados por sua capacidade de adquirir conhecimentos constantemente (FEIJÓ E VALENTE, 2004). Essa teoria explica como os processos de criação, manutenção e renovação da vantagem competitiva provêm dos recursos internos na firma. Os recursos são a combinação de competências, capacidades ("capabilities") e habilidades ("skills"), que determinam a base do conhecimento produtivo e organizacional. Por isso, constituem-se como vantagem competitiva capaz de gerar heterogeneidade e retorno (lucratividade) (KRETZER, 2002).

Nos trabalhos de autores neoschumpeterianos, são detectados avanços que ampliam o debate. Cabe ressaltar que nesse arcabouço teórico denominado evolucionário está presente a crença de que os indivíduos possuem racionalidade limitada, no sentido cunhado por Simon em 1950. Difere-se, portanto, da racionalidade substantiva dos neoclássicos, na medida em que os indivíduos estão suscetíveis a cometer erros e omissões, bem como a apresentar comportamento satisfatório e não ótimo (STEINGRABER E FERNANDES, 2013).

A economia evolucionária entende que os sistemas econômicos são os cenários onde as empresas concorrentes buscam diferenciais competitivos, em ambiente de mudanças e evolução. As firmas são impulsionadas pela inovação contínua. Os seres humanos são fundamentais nesse processo, pois podem agir, deliberadamente, no processo de inovação, ao pensar em novas soluções, realizar pesquisas e apresentar novas ideias.

Nelson (2012), afirma que parcela considerável do comportamento humano é vista como induzida, de forma relativamente automática, pelo contexto. Hábitos, rotinas, costumes, desempenham um papel importante na teoria econômica evolutiva. Alguns desses podem envolver padrões de comportamentos sofisticados, que exigem esforços cognitivos consideráveis e tempo de aprendizado, mas uma vez aprendidos, tornam-se, significativamente, automáticos.

O conjunto de habilidades necessárias para desenvolver competências da firma é chamado de rotinas. Essa padronização de comportamentos possibilita o bom funcionamento da firma e ordena as decisões por relevância. Ademais, define o conjunto de habilidades que precisam ser desenvolvidas ou aprimoradas. É plausível sustentar o argumento de que o conhecimento seja a memória da firma, a qual reside nas rotinas da organização. A rotina contém o estoque de conhecimento específico da empresa. A firma incorpora a rotina, na medida em que a utiliza, constantemente, tal como os indivíduos internalizam suas habilidades empregando-as. Além disso, a "memória" da firma vai além dos seus registros formais (NELSON E WINTER, 1982). Nelson e Winter (1982) baseiam-se no conceito de rotinas e as qualificam como a origem e o destino dos conhecimentos na firma (POPADIUK e RICCIARDI, 2011).

A firma pode ser considerada um repositório de conhecimento produtivo idiossincrático. Isso faz com que as empresas se distingam, mesmo que atuem em linhas de produto ou serviço parecidas com atividades empresariais semelhantes (NELSON \& WINTER, 1982). Em complemento, as rotinas, para essa teoria, são definidas como os "genes", de forma análoga à biologia, e se caracterizam por ter atributos persistentes e capazes de determinar os comportamentos possíveis das firmas. Contudo, isso não ocorre em totalidade, pois o comportamento concreto, passível de ser verificado, também irá depender do ambiente no qual a firma está imersa. Entende-se que as rotinas são hereditárias, no sentindo de serem repassadas de geração em geração e são selecionáveis, na medida em que umas podem sair-se melhor, comparativamente, 
a outras. As que se destacarem irão aumentar sua participação no ramo de atividade em que pertence (NELSON \& WINTER, 1982).

Adicionalmente, a firma, como um todo, é permeada de conhecimento, e este não pode ser reduzido a um único indivíduo, mas deve ser analisada no agregado de competências e habilidades dos indivíduos que a compõem. Esse conhecimento será refletido na "forma de fazer as coisas" da firma e a acumulação do conhecimento tecnológico, por exemplo, não é um processo que pode ser facilmente codificado (MARINS, 2007). Constata-se que aquilo que está "por trás" das rotinas são as habilidades dos indivíduos. De acordo com Nelson e Winter (1982), tais aptidões permitem aos indivíduos cumprir as tarefas. O modus operandi de uma firma condiz com o seu conjunto de habilidades, o que permite que as firmas tenham características próprias dependendo, desta forma, das capacidades individuais.

A rotina demonstra o "modo como as coisas são feitas" de forma coletiva. Para ser posta em prática não precisa, necessariamente, de reflexão, de modo que podem ser aplicadas: sem deliberação, atenção explicita ou consciência (NELSON E WINTER, 2002). Destarte, as firmas na ótica neoschumpeteriana são modeladas e contêm capacidades e regras de decisão, que se modificam ao longo do tempo com esforços deliberados para superação de problemas e eventos aleatórios. Em analogia com a seleção natural da biologia, o mercado determina (seleciona) quais firmas serão lucrativas e, por conseguinte, quais irão "sobreviver" (NELSON \& WINTER, 1982).

Adicionalmente, Giovani Dosi (1982), ao desenvolver o conceito de "paradigma tecnológico", associou esse conceito às "rotas" de aprendizado propiciado pelo conhecimento, já que um paradigma tecnológico pode ser definido como um conjunto de ferramentas de compreensão, que são compartilhadas por um grupo, com vistas a encontrar soluções possíveis para problemas de determinada área. Portanto, salienta-se a importância do conhecimento acumulado na firma, o qual depende de cada indivíduo ou equipe no processo, que, por seu turno, concretiza o paradigma com suas crenças, compreensões e experiências exclusivas.

A trajetória tecnológica é composta também de um processo em que a aprendizagem é imprescindível. Este processo constitui-se de três elementos, a saber: i) a oportunidade (possibilidade de um paradigma seguir certa trajetória); ii) a apropriabilidade (capacidade do indivíduo inovador se apropriar dos conhecimentos contidos no paradigma); e iii) a cumulatividade (noção de que o progresso técnico possui natureza cumulativa) (CIMOLI \& DOSI, 1992).

As diferenciações das firmas, referentes às suas características, comportamentos e desempenhos remetem à noção de competência. Esta, por seu turno, é uma característica distintiva no contexto social e organizacional. Representa como os indivíduos na firma armazenam conhecimento em seus procedimentos, normas e regras, ou seja, como aprendem. Os indivíduos pertencentes à fïrma acumulam conhecimento ao longo do tempo, aprendendo na interação com os outros membros. Ademais, se diferem por apresentar distintas capacidades de representação, relacionadas ao meio em que vivem e também possuem capacidades cognitivas díspares. Por isso, é necessário que a firma possua formas de gerenciar o conhecimento que garanta convergência com os processos de aprendizagem e desenvolvimento das competências (DOSI E MARENGO, 1994).

Lundvall (2006) afirma que além da competência individual, há competência inerente às rotinas da firma e métodos de resolução de problemas. $\mathrm{O}$ autor, afim de compreender a gestão de conhecimento, esquematiza os quatro diferentes tipos de conhecimento, a saber: know what (saber o que) know why (sabe porquê), know how (saber como) e know who (saber quem). O Know-what refere-se ao conhecimento sobre fatos, por exemplo, quantas pessoas vivem em Nova York? Quais são os ingredientes das panquecas? Esse conhecimento aproxima-se do conceito de informação. O Know-why refere-se ao conhecimento científico presente em princípios e leis do movimento na natureza, na mente do ser humano e na sociedade. Este tipo de conhecimento é importante para o desenvolvimento tecnológico. Contém quadros interpretativos baseados na experiência e intuição. O Know-how refere-se às habilidades, ou seja, à capacidade de fazer algo, por exemplo, como operar uma máquina. O know-how torna-se importante na medida em que a divisão do trabalho se torna mais complexa. Refere-se a uma mistura de diferentes tipos de habilidades, incluindo habilidades sociais. Remete à compreensão de quais informações são necessárias e para qual finalidade devem ser usadas. Adicionalmente, incorpora a relevância das relações sociais com especialistas 
para que o conhecimento seja compartilhado e utilizado de forma eficiente. Normalmente, o know-what e o know why são mais fáceis de serem codificados que o Know-how e o Know-who.

Nonaka e Takeuchi (1995) advogam que é necessária a transformação, comunicação e repasse do conhecimento tácito dos empregados de uma empresa. Essas relações permitem o aprendizado coletivo (processos de transmissão de conhecimento iniciado pelos indivíduos que vão transbordar para a firma). Os autores, em sua teoria de criação de conhecimento organizacional, defendem a existência de interação das formas explícita e tácita de conhecimento.

Como o modelo teórico de Nonaka e Takeuchi será amplamente discutido mais adiante, cabe apresentar a sua consonância com as abordagens teóricas mencionadas. Penrose (1959) e Nonaka (1995) compartilham da visão de que as organizações devem estar focadas na compreensão do modo como o conhecimento é criado e utilizado, pois, assim, seria possível utilizar melhor os recursos internos e desenvolver produtos e serviços diferenciados. Ademais, a gestão estratégica do conhecimento é vista como um processo efetivo para sustentar a vantagem competitiva empresarial (CECEZ-KECMANOVIC, 2005; WONG, WICKHAM e HALL, 2013). Adicionalmente, Penrose (1959) e Nonaka (1994) possuem a perspectiva de que o conhecimento é algo criado diretamente pelos indivíduos a partir de novas ideias que conduzem ao aprendizado e à inovação. A firma é um arranjo em que o conhecimento é depositado e utilizado pelos indivíduos (ASSUDANI, 2005).

Enquanto autores neoschumpeterianos avaliam a gestão de conhecimento em um contexto econômico mais amplo, Nonaka \& Takeuchi o faz em um contexto intrafirma. Com poucas exceções (por exemplo, Nelson e Winter, 1982; Nonaka e Takeuchi, 1995), outros autores propuseram uma teorização que adota uma perspectiva positivista do conhecimento, a qual leva pouco em conta os milênios de debate sobre a natureza problemática do conhecimento humano (SPENDER, 1996).

Nonaka e Takeuchi enfatizam a forma como a criatividade individual contribui para o crescimento do conhecimento coletivo, enquanto Nelson e Winter se concentram nos processos de aprendizagem extraracional (além do racional), ou seja, a empresa aprende e passa esse aprendizado para os seus empregados, que os internaliza, muitas vezes de forma não intencional (SPENDER, 1996). Nonaka e Takeuchi (1995), em convergência com o trabalho de Lundvall e Borras (1998), apontam que o processo de geração e exploração de conhecimento requer uma interação dinâmica e uma transformação de formas de conhecimento tácito e codificado, bem como exigem uma forte interação de pessoas dentro das firmas. Assim, o processo de criação de conhecimento torna-se cada vez mais inserido em várias formas de redes (nos níveis regional, nacional e internacional) (ASHEIM, 2007).

Em sincronia com esse pensamento, Nonaka teoriza que a transferência entre conhecimento tácito e codificado é um processo que ocorre continuamente em espirais: o conhecimento tácito torna-se codificado quando são feitas tentativas de comunicá-lo; o conhecimento recém-codificado é interpretado e processado pelo receptor, e se torna parte da base de conhecimento tácito desse indivíduo. Verifica-se um movimento contínuo e constante do conhecimento, à medida que ele é comunicado e interpretado pelos novos indivíduos. Dosi (1988) já havia mencionado que no campo econômico deve haver estruturas para a valorização do conhecimento. Adicionalmente, afirma que as trocas comerciais entre os indivíduos são feitas mediante o conhecimento que cada um possui (CEFOLA, 2009).

Independente da abordagem macro ou micro da economia de conhecimento os autores mencionados entendem como essencial promover a partilha de conhecimentos através da criação de acesso a conhecimento e estratégias de contextos organizacionais, bem como fomentar relações entre os funcionários que promovam a aprendizagem interativa. De acordo com Silva e Ferreira (2009), apud Penrose (1959, p.123),

A concepção da firma adianta uma série de atributos que são destacados na literatura sobre gestão. Pode-se mencionar em primeiro lugar, a necessidade de se pensar que a firma pressupõe o trabalho em equipe, que demanda tempo para ser constituído e para ser, progressivamente incrementado. Em segundo lugar, o crescimento da firma está associado à acumulação de conhecimento em seu interior, e está sob o controle de suas equipes. Sendo assim, o terceiro elemento está relacionado ao conhecimento tácito dos membros da equipe e ao aprendizado organizacional. O conhecimento nascido da experiência é central para que a gerência desenvolva qualificações e conhecimento técnico que não são facilmente codificados. 
Nelson e Winter (1982) afirmam que a firma fornece o contexto em que o corpo de conhecimento tácito e explícito é selecionado pela interação com a realidade econômica externa. Na sequência, esse corpo é armazenado em rotinas disponíveis, em particular, para futuras gerações de profissionais da empresa, e é "recuperado" através das rotinas.

Dosi e Nelson (2010) afirmam que o conhecimento científico e o tecnológico compartilham, em diferentes extensões, algum nível de "tacitividade". Ademais, a cumulatividade, atributo do paradigma tecnológico, incorpora o conhecimento explícito e tácito, este, mediante à especificidade do trabalho desenvolvido e é propiciado pela experiência profissional. A sua apropriação é difícil, pois há dificuldade na sua transformação em um "produto" comercializável no mercado (CIMOLI \& DOSI, 1992).

Lundvall (2006) cita que em uma economia de aprendizagem a construção de competências e a criação de novas formas de conhecimento tácito são cruciais para o desempenho econômico. Neste sentido, é necessário dar ênfase à promoção do compartilhamento do conhecimento, por intermédio da criação de acessos a conhecimentos codificados e explícitos, com processos organizacionais que promovam a aprendizagem interativa. Adicionalmente, as competências presentes nos indivíduos e no seu agregado, chamado como rotina, pode ser tácita e possui desafios para ser transformada em informação (LUNDALL 2006).

Para Nonaka e Takeuchi (1997), o conhecimento organizacional é o conhecimento compartilhado por indivíduos, embora transformados e amplificados. Os tipos conversão do conhecimento (externalização, internalização, socialização e combinação), que serão explicadas posteriormente, constituem o meio de conectar os dois modos de conhecimento (explícito e tácito) da empresa. A teoria da empresa busca, de forma geral, explicar os seguintes elementos: a) como os indivíduos geram o conhecimento tácito e b) como os problemas são resolvidos (SPENDER, 1996).

\section{APRESENTAÇÃO DO MODELO DE CONVERSÃO DE CONHECIMENTO NONAKA E TAKEUCHI (N \& T)}

O entendimento de que o conhecimento não é privado, mas sim social e que a obtenção de conhecimento, pelo indivíduo, somente é possível mediante o contato com novas experiências foi desenvolvida por Polanyi e apropriada por Nonaka (1994). Este autor acrescenta fatores, tais como: a possibilidade de criação, a aprendizagem e o reconhecimento do novo, os quais são fenômenos que se apresentam como fundamentais para o processo de criação de conteúdos que levam às inovações (LEONARDI E BASTOS, 2014). O conhecimento pessoal emerge da combinação de informação, interpretação, reflexão e experiência em uma situação particular. Para criar conhecimento organizacional o conhecimento individual (explícito e tácito) deve ser externalizado.

O aumento da importância do conhecimento na sociedade contemporânea depende de uma mudança de concepção em relação à inovação em grandes organizações empresariais (seja inovação técnica, inovação de produto, inovação estratégica ou organizacional) (NONAKA, 1994). Cumpre notar que o aumento de relevância do conhecimento leva à necessidade de aprimorar a compreensão a respeito da relação entre conhecimento e estratégia de negócio. Isso pode implicar no interesse das empresas em consolidar processos de gerenciamento de conhecimento e tecnologias, bem como levá-las a adotar a gestão de conhecimento como ferramenta de suas estratégias empresariais.

\subsection{A espiral do conhecimento}

Segundo Nonaka, Takeuchi \& Umemoto $(1996)^{4}$ há quatro padrões de conversão de conhecimento: a socialização, a externalização, combinação e internalização. O conjunto dessas quatro formas é denominado espiral do conhecimento. A socialização é um processo de compartilhamento de experiências que é capaz de criar conhecimento tácito, por exemplo, com a constituição de modelos mentais e habilidades técnicas que poderão ser compartilhadas. Todos os indivíduos podem adquirir conhecimento tácito

\footnotetext{
${ }^{4}$ O texto que segue baseia-se em (NONAKA, TAKEUCHI \& UMEMOTO, 1996)
} 
diretamente de outros sem, necessariamente, utilizar da linguagem verbal. Um exemplo disso pode ser visualizado por aprendizes (em artesanato ou outro artefato) que, ao trabalharem com seus mestres, aprendem através da observação, imitação e prática.

O segundo padrão de conversão do conhecimento, a externalização, é um processo de articulação do conhecimento tácito em conhecimento explícito. É um mecanismo de criação de conhecimento por excelência, na medida em que o conhecimento utiliza de metáforas, analogias, conceitos, hipóteses ou modelos. Quando se tenta conceituar uma imagem, há a expressão de sua essência, principalmente na forma de linguagem escrita, por isso é um ato de converter o conhecimento tácito em conhecimento articulável. No entanto, as expressões são muitas vezes inadequadas, inconsistentes e insuficientes. Mesmo com a existência de discrepâncias e lacunas entre imagens e expressões elas podem ajudar a promover a "reflexão" e a interação entre os indivíduos.

O modo de externalização da conversão do conhecimento é tipicamente visto no processo de criação de um conceito e é desencadeado pelo diálogo ou reflexão. O método utilizado, com frequência, para criar um conceito é combinar a dedução e a indução. Nesse sentido, em um projeto, a riqueza na utilização da linguagem figurativa e da imaginação, por parte dos líderes - na comunicação com os liderados, é um fator essencial para obter conhecimento tácito dos membros da equipe. Entre os quatro modos de conversão do conhecimento, a externalização é a chave para a criação de conhecimento, porque engendra novos conceitos explícitos, advindos do conhecimento tácito. A questão central que permite converter o conhecimento tácito em explícito (de forma eficaz e eficiente) é a utilização sequencial da metáfora, analogia e modelos. Assim, por intermédio da analogia o entendimento do desconhecido é facilitado e transforma-se em ponte entre a imagem potencial e o modelo concreto. Na medida em que os conceitos explícitos são criados, eles podem, então, ser modelados. Em um modelo lógico as contradições devem existir e os conceitos e as proposições devem ser expressas em linguagem sistemática e lógica coerente.

A terceira forma de conversão de conhecimento é chamada de combinação e apresenta-se como um processo de sistematização de conceitos a respeito do conhecimento. Essa conversão envolve a articulação de diferentes formas de conhecimento explícito. Os indivíduos trocam e combinam conhecimento através de meios presentes na firma, tais como: documentos, reuniões, conversas telefônicas ou redes de comunicação computadorizadas. A reconfiguração das informações existentes por meio da triagem, agregação, combinação e categorização do conhecimento explícito (como realizado em bancos de dados de computadores) podem levar a novos conhecimentos. A criação de conhecimento realizada em educação formal e treinamento nas universidades, geralmente, assume essa forma.

A quarta e última forma de conversão é denominada internalização e corresponde a um processo de incorporar conhecimento explícito no conhecimento tácito. Está intimamente relacionada com o "aprender fazendo". Quando as experiências através da socialização, externalização e combinação são internalizadas nas bases de conhecimento tácito dos indivíduos sob a forma de modelos mentais compartilhados ou de know-how técnico, eles são ativos valiosos. Para que a criação do conhecimento organizacional tenha o seu devido lugar, no entanto, o conhecimento tácito acumulado (no nível individual) precisa socializar-se e expandir-se para os outros membros organizacionais, iniciando, assim, uma nova criação espiral de conhecimento. A internalização depende das experiências baseadas em modelos mentais compartilhados. Para converter o conhecimento explícito em tácito é eficaz a produção de documentos, folhetos ou método oral (através da fala, por exemplo, palestras). A documentação permite a expressão de experiências e melhoramento do conhecimento tácito (DARROCH, 2003).

O conhecimento explícito para ser internalizado pode ser também formalizado, verbalizado ou diagramado em documentos, manuais ou histórias orais. A documentação ajuda os indivíduos a internalizar o que experimentaram e, assim, enriquecer o seu conhecimento tácito. Além disso, documentos ou manuais facilitam a transferência de conhecimento explícito para outras pessoas, ajudando-as a experimentar as experiências de outros indiretamente (ou seja, "reexperimentá-las"). A internalização também ocorre mesmo sem a "reexperimentação". Por exemplo, ao ler ou ouvir uma história de sucesso, alguns membros da firma podem sentir o realismo e a essência e a experiência que teve lugar no passado pode se alterar para um modelo mental tácito. Ademais, de acordo com Parente, Capuano e Nespoulous (1999), "um modelo mental é um constructo, localizado na memória episódica, que contém a representação subjetiva do sujeito: as associações pessoais, inferências e experiências prévias". Desta forma, quando o modelo mental é 
compartilhado com a maioria dos membros da firma, o conhecimento tácito torna-se parte da cultura organizacional. Esta prática é predominante no Japão, onde há abundância de livros e artigos sobre as empresas e seus líderes (NONAKA, TAKEUCHI \& UMEMOTO 1996). Os modos de conversão de conhecimento descritos serão ilustrados pela figura 1 abaixo.

Figura 1: A espiral do conhecimento

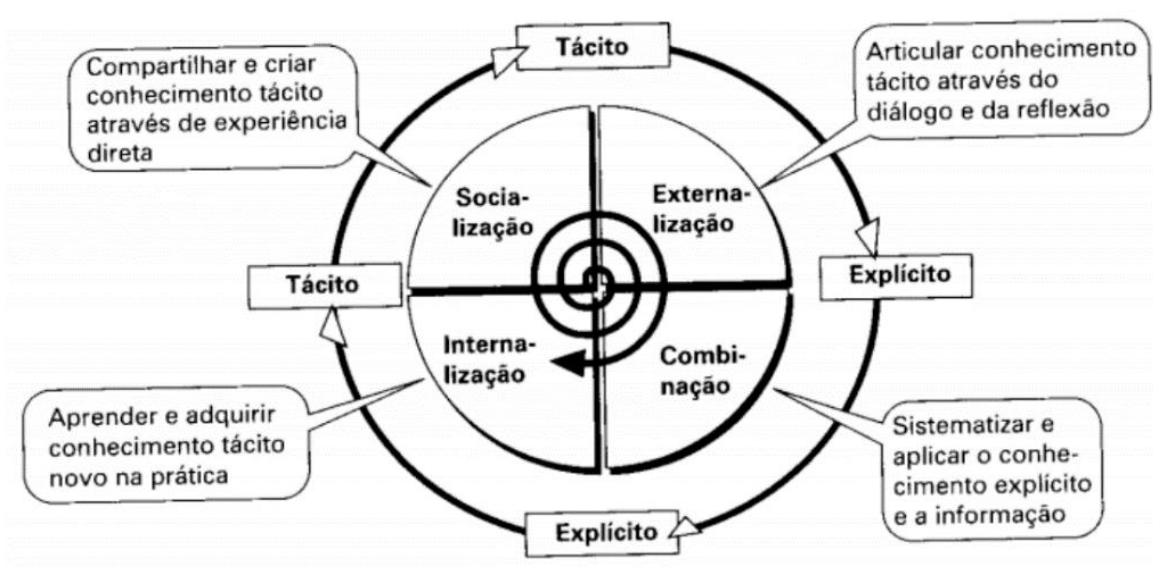

Fonte: Nonaka e Takeuchi (2008)

O comportamento da empresa pode ser explicado pela forma que ela lida com o conhecimento, levando em consideração a crença de que a firma não apenas o "processa", mas também o cria (NONAKA, 1997). Por exemplo, a inovação, que é uma forma chave de criação de conhecimento organizacional, não pode ser explicada, suficientemente, em termos de processamento de informações ou resolução de problemas. A inovação pode ser entendida como um processo no qual a firma lida com problemas e, então, desenvolve ativamente novos conhecimentos para resolvê-los. Neste processo, a inovação produzida por uma parte da organização cria um fluxo de informações e conhecimentos que podem desencadear mudanças nos sistemas de conhecimento mais amplos que os anteriormente observados (NONAKA, 1994). A forma com que a empresa lida e enfrenta os problemas permite que os seus profissionais desenvolvam competências, o que possibilita uma expansão de conhecimento.

Neste processo de absorção de novos conhecimentos, o indivíduo possui papel central, pois as ideias são formadas nas suas mentes e a interação entre os indivíduos, geralmente, desempenha um papel crítico no desenvolvimento e aperfeiçoamento dessas ideias. Ou seja, "comunidades de interação" contribuem para a ampliação e o desenvolvimento de novos conhecimentos. Embora essas comunidades possam abranger fronteiras departamentais ou mesmo organizacionais é importante definir uma dimensão adicional da criação de conhecimento organizacional, a qual está associada à extensão da interação social entre indivíduos que compartilham e desenvolvem o conhecimento. Isso é denominado como a dimensão "lógica" da criação de conhecimento (NONAKA, 1994).

\subsection{Estudos envolvendo a aplicação empírica do modelo de Nonaka e Takeuchi}

Para que seja realizada a investigação acerca das aplicações empíricas desse modelo serão analisados, de forma detalhada, cinco trabalhos. Cabe ressaltar que todos os trabalhos mencionados refletem contextos e realidades específicas, o que demostra que o modelo é flexível e adaptável a realidades distintas, ou seja, apresenta-se como uma temática multidisciplinar.

O primeiro trabalho possui autoria de Nonaka et. al, que foi o criador do modelo teórico, com vistas, a aplicar o seu modelo realizou um estudo denominado Creation Theory: A First Comprehensive Test, $\mathrm{O}$ 
objetivo do trabalho foi construir e testar, a partir da teoria de Nonaka (1994), um modelo de na criação de conhecimento. Para isso, utilizou-se da análise fatorial confirmatória com dados coletados de uma amostra de 105 gerentes japoneses. Os resultados forneceram suporte para a visualização da criação de conhecimento organizacional como um construto composto por quatro processos de conversão de conhecimento, quais sejam: socialização, externalização, combinação e internalização.

Nesta amostra, foi testada a hipótese de que o construto de criação de conhecimento consiste em quatro processos principais de conversão de conhecimento: socialização, externalização, combinação e internalização. Todos os quatro fatores ou processos de conversão de conhecimento explicam uma alta variação no construto de criação de conhecimento organizacional. Ou seja, os processos de conversão de conhecimento, quando existem, impactam positivamente e significativamente a criação de conhecimento nas empresas. A principal contribuição deste estudo é a operacionalização e o teste empírico da teoria da criação do conhecimento organizacional. O conhecimento tácito presente na firma é um componente relevante para sustentar a vantagem competitiva global.

Como segunda ilustração, tem-se o trabalho de Li, Huang e Tsai, (2009), que examina as relações entre orientação empreendedora, processo de criação de conhecimento e desempenho da firma. Ele é composto por uma amostra de dados de 165 empreendedores em Taiwan. Utiliza-se de estatística para testar o desempenho direto e efeitos indiretos da orientação empreendedora sobre o desempenho da empresa. O processo de criação de conhecimento - operacionalizado para refletir as dimensões de socialização, externalização, combinação e internalização - é utilizado como variável mediadora para explicar a relação entre orientação empreendedora e desempenho da empresa. Constata-se que a orientação empreendedora está positivamente relacionada ao desempenho da empresa e o processo de criação de conhecimento exerce um papel mediador nesse relacionamento.

A orientação empreendedora refere-se ao direcionamento estratégico da empresa para investimentos em novas práticas e métodos de produção. Ademais, pode ser vista como recurso que facilita uma empresa a superar os seus rivais e a torná-la capaz de auferir vantagem competitiva no mercado. Esse processo exige que os membros da firma se envolvam em atividades de conhecimento. Neste contexto, o principal objetivo deste trabalho foi examinar como a orientação empreendedora afeta o desempenho das empresas através do processo de criação de conhecimento.

Este modelo foi utilizado por três motivos, a saber: i) o modelo da SECI (Socialização, Externalização, Combinação e Internalização) é uma das poucas formulações teóricas de criação de conhecimento disponíveis que explora as inter-relações entre conhecimento explícito e tácito; ii) o modelo não se limita à transferência de conhecimento, mas também aborda a sua criação; iii) ele tem sido, amplamente, utilizado em muitas áreas de pesquisa, a exemplo da aprendizagem organizacional e do desenvolvimento de novos produtos. Ademais o trabalho partiu do pressuposto de que métricas financeiras (como participação de mercado a partir do crescimento das vendas, satisfação do cliente, valor da marca e etc.) são relevantes, mas não são suficientes para mensurar o desempenho da empresa.

No campo de pesquisa do empreendedorismo há uma falta de orientação sobre medição do desempenho, dada a dificuldade em definir a performance. Adicionalmente, foram desenvolvidas três hipóteses, a saber: i) a orientação empreendedora está positivamente relacionada com o desempenho da firma; ii) a orientação empreendedora está positivamente relacionada com o processo de criação de conhecimento; iii) o processo de criação de conhecimento estará positivamente relacionado com o desempenho da firma; iv) o processo de criação de conhecimento mediará as relações entre a orientação empreendedora e o desempenho da firma.

No tocante à amostra e à coleta de dados foi aplicado um questionário baseado na escala Likert. Como todas as medidas foram coletadas da mesma fonte, o teste de um fator de Harman foi usado para examinar o problema em potencial do viés comum de método. Esses autores desenvolveram um modelo conceitual para examinar o papel mediador do processo de criação de conhecimento na relação entre orientação empreendedora e desempenho da empresa. Os resultados mostram que a orientação empreendedora pode melhorar positivamente o desempenho da empresa. Não obstante, se adicionarmos o processo de criação de conhecimento como um mediador, a relação entre orientação empreendedora e desempenho da empresa, que é diretamente positiva, ganha um reforço, ou seja, se torna mais forte. Isso significa que a orientação empreendedora influencia indiretamente o desempenho da empresa ao influenciar 
o processo de criação do conhecimento. Assim, o processo de criação de conhecimento desempenha um papel mediador através do qual a orientação empreendedora beneficia o desempenho da empresa.

O terceiro exemplo da aplicação do modelo teórico de conversão de conhecimento pode ser verificado por intermédio do trabalho de Tharanga Goonesekera (2010). A autora argumenta que o gerenciamento do conhecimento é amplamente utilizado como parte de sua estratégia de negócios das empresas. No entanto, apesar dessa crescente atenção ao papel da gestão do conhecimento, as organizações não têm critérios definidos para descobrir se são ou não bem-sucedidas nessa gestão. Neste contexto, a sua pesquisa possui como objetivo medir níveis de maturidade no gerenciamento do conhecimento das organizações, com vistas a preencher essa lacuna metodológica. Para a sua abordagem inovadora foi utilizado o método Fuzzy, com foco no departamento de produção das organizações. O tamanho das organizações foi segmentado em duas categorias: pequenas e médias organizações. Os participantes eram dos departamentos de produção e ocupavam os cargos de diretores, gerentes ou supervisores. O tamanho total da amostra era de 108 unidades. O objetivo da pesquisa foi desenvolver um modelo para que pudesse se mensurar os níveis de maturidade da gestão de conhecimento no setor de produção de organizações industriais.

Para concretizar o objetivo foi utilizado o Information System Sucess Model (D\&S Sucess Model) (DELONE \& MCLEAN, 1992, 2003) e o modelo de conversão de conhecimento (NONAKA, TOYAMA, \& NAGATA, 2000; NONAKA, TOYAMA, \& HIRATA, 2008) personalizando-os dentro do contexto da gestão do conhecimento e da teoria da Lógica Fuzzy. O modelo $D \& S$ é utilizado para medir a performance multidimensional dos sistema de informação na organização. Para tal análise definem-se os seguintes aspectos: i) qualidade da informação (que o setor é capaz de armazenar, entregar ou produzir) ;ii) qualidade do sistema (atributos técnicos); iii) qualidade de serviço (afeta diretamente as intenções de uso e a satisfação do usuário com o sistema, o que, por sua vez, afeta os benefícios líquidos produzidos pelo sistema); iv) uso do sistema ou intenções de uso (são influenciadas pela informação, sistema e qualidade do serviço; v) satisfação do usuário (percepção da satisfação advinda da utilização); vi) rede de benefícios (advindos da utilização) e; iv) benefícios do sistema (os benefícios líquidos do sistema são afetados pelo uso do e pela percepção de benefícios na utilização).

Foi mensurado para cada tipo de conversão de conhecimento (socialização, externalização, combinação e internalização), seu nível respectivo (inicial, intermediário ou avançado). A partir disso, foram propostos dois questionamentos. Primeiro, "quais são os níveis de maturidade da gestão de conhecimento no departamento de produção das organizações?". Segundo, "qual seria a ferramenta para medir o nível de maturidade da gestão do conhecimento na área de produção das organizações"? Para tal propósito, foram unidos os métodos D\&S Sucess Model e Conversão de Conhecimento. Além disso, foi aplicada a Lógica de Conjuntos Fuzzy em formado triangular. A regra de categorização Fuzzy foi derivada da seguinte equação: $P=[0,0,33,0,66,1]$. Em que $(\leq 0,33$ categoria inicial; $\leq 0,66$ categoria intermediária $\mathrm{e} \leq 1$ categoria avançada). Os resultados permitiram a obtenção de maior esclarecimento acerca dos níveis de maturidade de conhecimento em cada aspecto vinculado ao departamento de produção. Ademais, os gestores podem utilizar essas informações para justificar os investimentos em técnicas e estratégias de gestão do conhecimento organizacional, com vistas a gerar diferenciais competitivos e fomentar suas práticas inovativas.

O trabalho de Aidin Ghaffari Oskouei (2013) também ilustra a aplicação do modelo de conversão de conhecimento. No estudo argumenta-se que devido aos desafios concorrenciais as empresas devem construir diferenciais competitivos. Neste sentido, o conhecimento foi identificado como um recurso organizacional fundamental, que, se usado de forma eficaz, pode oferecer vantagem competitiva. Por isso, as empresas devem empreender esforços no sentido de identificar, capturar e compartilhar conhecimento. O primeiro passo na implantação da prática de gestão do conhecimento de uma firma é determinar qual o seu nível de conhecimento. O autor utiliza o modelo de Nonaka e Takehuchi (N\&T), pois considera que, em constraste com outros modelos este se concentra no conhecimento explícito e implícito e na maneira como eles se modificam. Por essa característica ele pode ser considerado um dos mais relevantes modelos cognitivos. Adicionamente, mostra como os conhecimentos são produzidos em todos os níveis (individual, grupal e organizacional). O fito deste estudo foi investigar e determinar o nível de conhecimento do município de Mashhad baseado no modelo N\&T. Esse objetivo desmembrou-se na resposta às seguintes 
questões: $O$ modelo de $N \& T$ é o modelo cognitivo eficiente? e Qual o nível de conhecimento da municipalidade de Mashhad a partir do modelo de $N \& T$ ?

A pesquisa é aplicada no município de Mashhad, segunda maior cidade do Irã. Foi aplicado um questionário em que os entrevistados tinham que apresentar a sua percepção (concordância ou discordância) relacionada às proposições do questionário. Os respondentes (que totalizaram $292 \mathrm{em} \mathrm{2013)} \mathrm{eram} \mathrm{gerentes}$ e especialistas com alto nível educacional. Todos os departamentos foram contemplados: transporte; serviços urbanos; civil e técnico; arquitetura e planejamento urbano; social e cultural; administrativo e financeiro, e planejamento e desenvolvimento. Depois da análise estratificada por departamentos foi determinado o nível geral de conhecimento do município de Mashhad. Como resultado, têm-se as seguintes conclusões: relacionada à primeira hipótese, "o modelo $N \& T$ é o modelo cognitivo eficaz na determinação do nivel de conhecimento?". Constata-se, que por abordar a conexão entre os dois tipos de conhecimento (explícito e tácito), e considerar o indivíduo como elemento central desse processo de conversão, esse modelo é eficiente. Com relação à segunda problemática que era de determinar o nível de conhecimento do municipio usando o modelo de $\mathrm{N} \& \mathrm{~T}$. Conclui-se que os investimentos relacionados ao conhecimento estavam em nível médio e baixo, por isso foram definidos como críticos. Assim, a fim de avançar na gestão de conhecimento, um projeto baseado em KM (Knowledge Managemente) deve ser implementado.

Por fim, trabalhos mais recentes também realizaram esforços com o fito de ampliar os estudos e as aplicações do modelo de Nonaka e Takeuchi. Pode-se citar o seguinte estudo de Akhavan, Nabizadeh e Rajabion (2017). O objetivo do trabalho foi fornecer um padrão para a implementação da gestão do conhecimento, em nível nacional, além de também medir o grau de correlação entre os conceitos existentes. Ele pode, ainda, apoiar os líderes a gerenciar ativos e conhecimento em nível nacional. Foi apresentada, anteriormente, a análise de estudos de casos relacionados à conversão de conhecimento em diversas localidades, tais como: Austrália, França, Taiwan, Alemanha, América do Norte, Japão e China. Nestes países, a gestão de conhecimento é analisada à luz da teoria de Nonaka e Takeuchi. Posteriormente, com base em outras referências foi realizada uma abordagem híbrida qualitativa-quantitativa como metolodologia de pesquisa. Optou-se pelo método Dematel Fuzzy. O método Dematel é foi aplicado para resolver problemas complexos, com apoio de representação visual, a partir de diagrama de relação de impacto e inter-relações entre os critérios. Além disso, aplicou-se a Lógica Fuzzy, pois existe a concepção de que, não raro os tomadores de decisão (especialistas) tendem a expressar suas avaliações com base em experiências passadas, raciocínio, estimativas e forma de linguagem subjetiva.

Adicionamente foi realizada uma categorização dos conceitos relativos à gestão de conhecimento, os quais se referem aos principais fatores relacionados à gestão do conhecimento em nível nacional. Conclui-se que os países demonstram uma tendência a implementar a gestão do conhecimento, a fim e avançar no sentido de uma sociedade e de uma economia baseadas no conhecimento. A cultura é o fator mais importante na consolidação da gestão do conhecimento, tanto em nível organizacional quanto em âmbito nacional. Por isso, é necessário sensibilizar os indivíduos e firmas a partir da demonstração de vantagens e consequências da implementação de um projeto de gestão do conhecimento. Os trabalhos citados serão apresentados, de forma resumida na tabela 2 .

Tabela 2: Exemplos empíricos do modelo de conversão de conhecimento N\&T. 


\begin{tabular}{|c|c|c|c|c|c|c|}
\hline \multicolumn{7}{|c|}{ APLICAÇÃO DO MODELO DE CONVERSÃO DE CONHECIMENTO DE NONAKA E TAKEUCHI } \\
\hline AUTOR & TRABALHO & ANO & OBJETIVOS & \begin{tabular}{|c|} 
JUSTIFICATIVA \\
\end{tabular} & METODOLOGIA & PRINCIPAIS RESULTADOS \\
\hline Nonaka et al. & $\begin{array}{l}\text { Creation Theory: A First } \\
\text { Comprehensive Test }\end{array}$ & 1994 & $\begin{array}{c}\text { Construir e testar a partir da teoria } \\
\text { de Nonaka (1994) um modelo de na } \\
\text { criação de conhecimento }\end{array}$ & $\begin{array}{l}\text { Organização que lide dinamicamente com } \\
\text { um ambiente em mutação não deve } \\
\text { apenas processar informações com } \\
\text { eficiência, mas também criar informações } \\
\text { e conhecimentos }\end{array}$ & $\begin{array}{l}\text { Análise fatorial } \\
\text { confirmatória }\end{array}$ & $\begin{array}{l}\text { Todos os quatro fatores ou processos de } \\
\text { conversão de conhecimento } \\
\text { (socialização, externalização, } \\
\text { combinação e internalização) explicam } \\
\text { uma alta variação no construto de } \\
\text { criação de conhecimento organizacional. }\end{array}$ \\
\hline $\begin{array}{l}\text { Li, Huang e } \\
\text { Tsai }\end{array}$ & $\begin{array}{c}\text { Entrepreneurial } \\
\text { orientation and firm } \\
\text { performance: } \text { The role of } \\
\text { knowledge creation } \\
\text { process, }\end{array}$ & 2009 & $\begin{array}{c}\text { Examinar como a orientação } \\
\text { empreendedora adotada afeta o } \\
\text { desempenho das empresas através do } \\
\text { processo de criação de conhecimento. }\end{array}$ & $\begin{array}{c}\text { Medidas financeiras, tais como: } \\
\text { participação de mercado a partir do } \\
\text { crescimento das venda; satisfação do } \\
\text { cliente; valor da marca etc. são relevantes } \\
\text { mas não suficientes para mensurar o } \\
\text { desempenho da empresa. }\end{array}$ & $\begin{array}{l}\text { Análise fatorial } \\
\text { confirmatória }\end{array}$ & $\begin{array}{c}\text { Os resultados mostram que a orientação } \\
\text { empreendedora pode melhorar } \\
\text { positivamente o desempenho da } \\
\text { empresa. Assim, o processo de criação } \\
\text { de conhecimento desempenha um papel } \\
\text { mediador através do qual a orientação } \\
\text { empreendedora beneficia o desempenho } \\
\text { da empresa. }\end{array}$ \\
\hline $\begin{array}{c}\text { Tharanga } \\
\text { Goonesekera }\end{array}$ & $\begin{array}{c}\text { Measuring knowledge } \\
\text { management maturity } \\
\text { levels in the manufacturing } \\
\text { sector using fuzzy logic } \\
\text { theory". }\end{array}$ & 2010 & $\begin{array}{c}\text { Medir níveis de maturidade em } \\
\text { gestão do conhecimento organizações, } \\
\text { no setor de produção da indústria, } \\
\text { com vistas, a preencher essa lacuna } \\
\text { metodológica. }\end{array}$ & \begin{tabular}{|} 
Apesar dessa crescente atenção ao papel \\
da gestão do conhecimento, as \\
organizações não têm critérios definidos \\
para descobrir se são ou não bem \\
sucedidas nessa gestão
\end{tabular} & \begin{tabular}{|c|} 
Lógica Fuzzy: \\
Information System \\
Sucess Model ( D\&S \\
Sucess Model) e o \\
modelo de \\
conversão de \\
conhecimento \\
\end{tabular} & $\begin{array}{l}\text { Os resultados evidenciaram que foi } \\
\text { possível mensurar os dos níveis de } \\
\text { maturidade de conhecimento em cada } \\
\text { aspecto vinculado ao departamento de } \\
\text { produção e com isso ter mais clareza } \\
\text { para o investimento de iniciativas } \\
\text { baseadas em gestão de conhecimento. }\end{array}$ \\
\hline $\begin{array}{l}\text { Aidin Ghaffari } \\
\text { Oskouei }\end{array}$ & \begin{tabular}{|} 
Investigation of Knowledge \\
Management based on \\
Nonaka and Takeuchi \\
Model in Mashhad \\
Municipality
\end{tabular} & 2013 & $\begin{array}{l}\text { Investigar e determinar o nível de } \\
\text { conhecimento do município de } \\
\text { Mashhad baseado no modelo } \\
\text { Nonaka\&Takeuchi }\end{array}$ & \begin{tabular}{|c|} 
O conhecimento foi identificado como um \\
recurso organizacional significativo, que, \\
se usado de forma eficaz, pode oferecer \\
vantagem competitiva. Por isso, as \\
empresas devem empreender esforços \\
como identificar, capturar e compartilhar \\
conhecimento. O primeiro passo na \\
implantação da prática de gestão do \\
conhecimento é determinar qual seu nível \\
de conhecimento
\end{tabular} & $\begin{array}{c}\text { Análise de regressão } \\
\text { múltipla pelo } \\
\text { software estatístico } \\
\text { SPSS }\end{array}$ & $\begin{array}{l}\text { Conclui-se à partir de sistematização que } \\
\text { os investimentos relacionados ao } \\
\text { conhecimento estão em nível médio e } \\
\text { baixo, por isso foram classificados em } \\
\text { área crítica. Assim, a fim de avançar na } \\
\text { gestão de conhecimento, um projeto } \\
\text { baseado em } K M \text { deve ser implementado. }\end{array}$ \\
\hline Akhavan, et al. & $\begin{array}{l}\text { Introducing knowledge } \\
\text { management pattern at } \\
\text { national level applying } \\
\text { grounded theory method } \\
\text { and fuzzy dematel }\end{array}$ & 2017 & \begin{tabular}{|c|} 
Fornecer um padrão da \\
implementação da gestão do \\
conhecimento em nível nacional e \\
também medir o grau de correlação e \\
importância entre os conceitos \\
existentes.
\end{tabular} & $\begin{array}{c}\text { Devido a difusão do conceito de } \\
\text { conhecimento entre países. É relevante a } \\
\text { criação de um guia para implementação } \\
\text { da gestão do conhecimento em nível } \\
\text { nacional. Pode ainda, apoiar os líderes a } \\
\text { gerenciar ativos e conhecimento em nível } \\
\text { nacional. }\end{array}$ & Domatel Fuzzy & $\begin{array}{c}\text { Foi criado um padrão com os principais } \\
\text { itens de gestão de conhecimento. } \\
\text { Adicionalmente, inclui-se o argumento } \\
\text { de que os países demonstram uma } \\
\text { tendência a implementar a gestão do } \\
\text { conhecimento a fim de avançar para a } \\
\text { sociedade e economia baseadas no } \\
\text { conhecimento. A cultura é o fator mais } \\
\text { importante nesse processo. }\end{array}$ \\
\hline
\end{tabular}

Fonte: elaboração própria

\section{CONCLUSÃO}

Para compreender como a interconexão entre as dimensões (tácita e explícita) do conhecimento é relevante para geração de capacidades competitivas organizacionais, optou-se por organizar a reflexão acerca do conhecimento a partir de uma ótica heterodoxa, relacionada à importância do aprendizado e conhecimento para a firma. Ademais, essa discussão adensou-se com a teoria de Nonaka e Takeuchi (N\&T), a qual foi inovadora na sistematização de gestão de conhecimento organizacional. Adicionalmente, mostrou-se que essa teoria é passível de aplicação empírica.

Acerca das teorias heterodoxas, Penrose (1959) desenvolve a sua teoria baseada nas capacidades e recursos da firma. Nelson e Winter (1982) conceitua a rotina como a forma que o conhecimento é armazenado nas organizações. Dosi (1982) argumenta que o paradigma se constitui, basicamente, no conhecimento compartilhado. Lundvall (1988) desenvolve uma teorização acerca do conhecimento baseado no aprendizado tecnológico (nas dimensões know what, know why, know how, know who). Nonaka e Takeuchi (1997) sistematizam a gestão de conhecimento em nível micro.

Depois de abordar o debate entre correntes teóricas este trabalho apresentou e sistematizou o modelo teórico de conversão de conhecimento de Nonaka e Takeuchi (1997). Esse modelo mostra como o conhecimento é gerenciado em nível micro a partir de suas dimensões explícita (codificação) e tácita (presente na mente dos indivíduos), geralmente cristalizada a partir da experiência. O modelo está focado no diálogo contínuo entre os tipos de conhecimento tácito e explicito. Ele propõe que o conhecimento atua na firma em formato de espiral e pode crescer na medida em que é compartilhado. Ademais, esquematiza quatro tipos de conversão do conhecimento, a saber: socialização, internalização, externalização e combinação. Por fim, o seu trabalho empírico é apresentado. Posteriormente, são apresentados trabalhos empíricos relevantes que demostram as repercussões positivas relacionadas a possibilidade de mensuração da gestão de conhecimento organizacional. A partir dessa mensuração constatou-se maior clareza quanto às iniciativas para investimentos nessa área. 
Conclui-se que devido aos desafios concorrenciais as firmas devem construir diferenciais competitivos. Neste sentido, o conhecimento apresenta-se como recurso organizacional fundamental, que, se usado de forma eficaz, pode oferecer vantagem competitiva. Por isso, as firmas devem empreender esforços no sentido de identificar, capturar e compartilhar conhecimento. Nesse contexto, a gestão de conhecimento deve ser compreendida como um modelo de negócio interdisciplinar, que incorpora a geração de conhecimento a partir dos relacionamentos internos da firma. Ademais, as vantagens competitivas das firmas não podem ser constituídas apenas por seus aspectos técnicos. O conhecimento se desenvolve se a empresa atua como uma comunidade social com habilidades de orientar, comunicar, traduzir e difundir o conhecimento. Os indivíduos possuem papel fundamental nesse processo ao possuirem o potencial de compartilhamento de conhecimento. A firma, neste contexto, é a estrutura capaz de fomentar o aprendizado.

\section{REFERÊNCIAS BIBLIOGRÁFICAS}

AKHAVAN, Peyman; NABIZADEH, Masoumeh; RAJABION, Lila. Introducing knowledge management pattern at national level applying grounded theory method and fuzzy dematel. VINE Journal of Information and Knowledge Management Systems, v. 47, n. 3, p. 372-394, 2017.

ANCORI, Bernard; BURETH, Antoine; COHENDET, Patrick. The economics of knowledge: the debate about codification and tacit knowledge. Industrial and corporate change, v. 9, n. 2, p. 255-287, 2000.

ARAUJO, Luis Cesar G. de; GARCIA, Adriana Amadeu. Gestão de pessoas: estratégias e integração organizacional. In: Gestão de pessoas: estratégias e integração organizacional. 2009.

ASHEIM, Bjorn et al. Constructing knowledge-based regional advantage: implications for regional innovation policy. International Journal of Entrepreneurship and Innovation Management, v. 7, n. 25, p. 140-155, 2007.

ASSUDANI, Rashmi H. Catching the chameleon: understanding the elusive term "knowledge". Journal of Knowledge Management, v. 9, n. 2, p. 31-44, 2005.

BROOKS, Martin; SMITH, Jack. KNOWLEDGE MANAGEMENT: THE NEW CHALLENGE FOR FIRMS AND ORGANISATIONS. OECD Conference - Ottawa, Canada, September 2000.

CARVALHO, RB de; FERREIRA, Marta Araújo Tavares. Tecnologia da Informação Aplicada a Gestão do Conhecimento. Coleção Tecnologia \&Informação, 2012.

CECEZ-KECMANOVIC, Dubravka. A sensemaking theory of knowledge in organizations and its application. In: Knowledge Management. Physica-Verlag HD, 2005. p. 55-74.

CEFOLA, Jacquelyn. The economic impact of knowledge. Routledge, 2009.

CIMOLI, Mario; DOSI, Giovanni. Tecnología y desarrollo. Algunas consideraciones sobre los recientes avances en la economía de la innovación. El cambio tecnológico hacia el nuevo milenio: debates y nuevas teorías. Barcelona: Içaria, p. 23-55, 1992.

CHAUÍ, Marilena. Convite à filosofia. 2. reimp. São Paulo: Ática, 2000.

COWAN, Robin; DAVID, Paul Allan; FORAY, Dominique. The explicit economics of knowledge codification and tacitness. Industrial and corporate change, v. 9, n. 2, p. 211-253, 2000.

COWAN, Robin; FORAY, Dominique. The economics of codification and the diffusion of knowledge. Industrial and corporate change, v. 6, n. 3, p. 595-622, 1997. 
DE CARVALHO, Maria Cecilia M. Construindo o saber: técnicas de metodologia científica. Papirus Editora, 1989.

DAVENPORT, T. H.; PRUSAK, L. Conhecimento empresarial: como as organizações gerenciam o seu capital intelectual. Rio de Janeiro: Campus, 1998.

DARROCH, Jenny. Developing a measure of knowledge management behaviors and practices. Journal of knowledge management, v. 7, n. 5, p. 41-54, 2003.

DIERICKX, Ingemar; COOL, Karel. ASSET STOCK ACCUMULATION AND THE SUSTAINABILITY OF COMPETITIVE ADVANTAGE: REPLY. Management Science, v. 35, n. 12, 1989.

DOSI, Giovanni. Technological paradigms and technological trajectories: a suggested interpretation of the determinants and directions of technical change. Research policy, v. 11, n. 3, p. 147-162, 1982.

DOSI, Giovanni; MARENGO, Luigi. Some elements of an evolutionary theory of organizational competences. The Theory of the Firm: Critical Perspectives on Business and Management, p. 50-73, 1994.

FEIJÓ, Carmem A.; VALENTE, Elvio. A firma na teoria econômica e como unidade de investigação estatística: evolução nas conceituações. Revista de Economia Contemporânea, v. 8, n. 2, 2004.

FORAY, Dominique et al. Tacit and codified knowledge. Chapters, 2007.

GOONESEKERA, Tharanga et al. Measuring Knowledge Management Maturity Levels in the Manufacturing Sector Using Fuzzy Logic Theory. 2012. Tese de Doutorado. La Trobe University.

KRETZER, J. Capacidades de desenvolvimento como fonte da sustentabilidade da vantagem competitiva: uma contribuição à visão baseada em recursos da firma. 2002. 239 f. 2002. Tese de Doutorado. Tese (Doutorado em Engenharia de Produção)-Centro Tecnológico, Universidade Federal de Santa Catarina, Florianópolis.

LENHARI, Luciana Cristina et al. Existe uma economia baseada no conhecimento? Uma análise do papel do conhecimento na economia. 2005.

LEONARDI, Juliana; BASTOS, Rogério Cid. Bases epistemológicas da teoria de criação de conhecimento organizacional. Perspectivas em Gestão \& Conhecimento, v. 4, n. 2, p. 3-18, 2014.

LI, Yong-Hui; HUANG, Jing-Wen; TSAI, Ming-Tien. Entrepreneurial orientation and firm performance: The role of knowledge creation process. Industrial marketing management, v. 38, n. 4, p. 440-449, 2009.

LUNDVALL, Bengt-Ake et al. Knowledge management in the learning economy. Danish Research Unit for Industrial Dynamics Working Paper Working Paper, n. 06-6, p. 3-5, 2006.

LUNDVALL, Bengt-Ake et al. Knowledge management in the learning economy. Danish Research Unit for Industrial Dynamics Working Paper Working Paper, n. 06-6, p. 3-5, 2006.

LUNDVALL, Bengt-Åke; BORRAS, Susana. Innovation Policy in the Globalising Learning EconomySummary. 1998. 
MARINS, Luciana Manhães. Economia, Tecnologia E Inovação: Da Teoria Da Firma À Gestão Da Inovaçã. Revista Eletrônica de Ciência Administrativa, v. 6, n. 1, p. 1, 2007.

MICHAEL, Polanyi. The tacit dimension. Peter Smith, Gloucester, Mass, 1966.

NELSON, Richard R. Human behavior and cognition in evolutionary economics. Biological theory, v. 6 , n. 4, p. 293-300, 2011.

NELSON, Richard R.; SIDNEY, G. Winter. 1982. An evolutionary theory of economic change. 2005.

NELSON, Richard R.; WINTER, Sidney G. Evolutionary theorizing in economics. The journal of economic perspectives, v. 16, n. 2, p. 23-46, 2002.

NONAKA, Ikujiro. A Dynamic Theory of Organizational Knowledge Creation. Organization Science, v. 5, n. 1, p. 14-37, February, 1994.

NONAKA, Ikujiro; TAKEUCHI, Hirotaka. The knowledge-creating company: How Japanese companies create the dynamics of innovation. Oxford university press, 1995.

NONAKA, lkujiro; TAKEUCHI, Hirotaka; UMEMOTO, Katsuhiro. A theory of organizational knowledge creation. International Journal of Technology Management, v. 11, n. 7-8, p. 833-845, 1996.

NONAKA, Ikujiro et al. Organizational knowledge creation theory: a first comprehensive test. International Business Review, v. 3, n. 4, p. 337-351, 1994.

NONAKA, Ikujiro; TAKEUCHI, Hirotaka. Teoria da criação do conhecimento organizacional. Gestão do conhecimento. Porto Alegre: Bookman, p. 54-90, 2008.

NONAKA, Ikujiro;TAKEUCHI, Hirotaka. Criação de conhecimento na empresa. Rio de Janeiro: Campus, 1997.

OSKOUEI, Aidin Ghaffari. Investigation of knowledge management based on Nonaka and Tekeuchi model in Mashhad Municipality. 2013. Tese de Doutorado. Eastern Mediterranean University (EMU)Doğu Akdeniz Üniversitesi (DAÜ).

PENROSE, Edith T. The theory of the growth ofthe firm. New York: Sharpe, 1959

POLANYI, Michael. The tacit dimension. University of Chicago press, 2009.

POPADIUK, Silvio; RICCIARDI, Giancarlo. Is knowledge conversion a source of Competitive Sustainable Advantage? an empirical analysis based from a Resource-based View perspective. Gestão \& Produção, v. 18, n. 1, p. 193-204, 2011.

SILVA, Antonio Braz de Oliveira; FERREIRA, Marta Araújo Tavares. Gestão do conhecimento e teoria da firma. Perspectivas em Ciência da Informação, v. 14, n. 3, p. 116-139, 2009.

SOO, Christine; MIDGLEY, David; DEVINNEY, Timothy. The process of knowledge creation in organizations. 2002.

SPENDER, J.-C. Making knowledge the basis of a dynamic theory of the firm. Strategic management journal, v. 17, n. S2, p. 45-62, 1996. 
STEINGRABER, R.; FERNANDEZ, R. G. A racionalidade limitada de Herbert Simon na Microeconomia. Revista Soc. Bras. Economia Política, São Paulo, n. 34, p. 123-162, fev., 2013.

TOMAÉL, Maria Inês; ALCARÁ, Adriana Rosecler; DI CHIARA, Ivone Guerreiro. Das redes sociais à inovação. Ciência da informação, v. 34, n. 2, p. 93-104, 2005.

ZAWISLAK, Paulo Antônio. A relação entre conhecimento e desenvolvimento: essência do progresso técnico. Análise, v. 6, n. 1, p. 125-149, 1995.

Winter, S. G. (1987). Knowledge and competence as strategic assets. In D. Teece (Ed.), The competitive challenge: Strategic for industrial innovation and renewal (pp. 159184). New York: Ballinger.

WONG, T. L.; WICKHAM, Mark; HALL, L. The Paradox of Training and Development: Knowledge Management in the Chinese Hospitality Industry Context. 2013. 